\title{
PARA ALÉM DO CAMPO DA VISÃO: MATERIAIS COMPLEMENTARES PARA A EDUCAÇÃO DE CRIANÇAS CEGAS E DE BAIXA VISÃO
}

\author{
BEYOND THE VISION: COMPLEMENTARY EDUCATIVE MATERIALS FOR BLIND AND \\ LOW VISION CHILDREN
}

Elizabeth Motta JACOB

Universidade Federal do Rio de Janeiro e.jacob@uol.com.br

\begin{abstract}
Resumo: Este artigo apresenta o trabalho que vem sendo realizado por professores e alunos da Universidade Federal do Rio de Janeiro com o apoio do Instituto Benjamin Constant no sentido de produzir material grafo tátil, lúdico com fins a desenvolver sensorialmente o aprendizado de crianças cegas e de baixa visão. Entendemos que as crianças cegas e de baixa visão têm plena capacidade de aprendizagem podendo se tornar cidadãos plenos. Para tanto é necessário que sua educação seja inclusiva e permita o aprimoramento de suas habilidades. Reconhecendo as características cognitivas do cego e da baixa visão, as apresentamos brevemente aqui. No sentido de também fundamentar o nosso trabalho a partir das alternativas ora em circulação, analisamos os tipos de publicação hoje existentes para este público e identificamos algumas carências. Numa sociedade em que a visão se tornou o sentido dominante, o material produzido para o público em questão priva-se muitas vezes de explorar outras dimensões estéticas evitando, com isso, a exploração criativa dos demais sentidos. Observando esta carência, nossa pesquisa volta-se para 0 desenvolvimento de livros, brinquedos e material de apoio didático com design voltado para este público. O material que estamos desenvolvendo tem como objetivo também ser utilizado como complementação pedagógica na educação infantil e primeiras séries do ensino fundamental, trabalhando no sentido de desenvolver multi-sensorialmente a criança cega e de baixa visão.
\end{abstract}

Palavras-chave: Educação inclusiva. Design. Material grafo-tátil.

\begin{abstract}
This article presents the work being carried out by professors and students of the Federal University of Rio de Janeiro with the support of the Benjamin Constant Institute in the sense of producing tactile, playful graphical material with the purpose of sensorially developing the learning of blind and low vision children. We understand that blind and low vision children totally capable for learning and can become citizens. For this, it is necessary that their education be inclusive and allow the improvement of their abilities. We briefly introduce the cognitive characteristics of blind and low vision here. We analyze the types of publications that exist today for this public In order identify their advantages and problems proposing alternatives. In a society where vision has become the dominant sense, the material produced for the public in question often deprives
\end{abstract}


itself of exploring other aesthetic dimensions, thus avoiding the creative exploration of the other senses. Observing this lack our research turns to the development of books, toys and didactic support material as we will demonstrate throughout the article. The material we are developing is also intended to be used as pedagogical complementation in early childhood education and first grade of elementary education working to develop multi-sensory skills.

Keywords: Inclusive education; design; tatile material.

\section{Introdução}

Este trabalho faz parte de nossos estudos desenvolvidos no sentido de contribuir para a produção de material didático, lúdico, estético e de forte apelo sensorial para auxiliar no processo aprendizagem de deficientes visuais. Deficiente visual é considerado aquele que tem perda parcial ou total da visão de ambos os olhos. Deste modo consideram-se cegas as pessoas que tem perda total ou capacidade ínfima de enxergar. Para esses há a necessidade do sistema Braille$^{1}$ para leitura e escrita. Já aqueles considerados de baixa visão possuem uma acuidade visual reduzida e conseguem ver imagens, identificar letras e sinais ampliados ou com o apoio de recursos óticos.

O objetivo deste projeto é contribuir para a criação de materiais educativos voltados para o público deficiente visual. Nosso trabalho consiste na produção de livros-objeto, jogos educativos e material de apoio a professores na transmissão de saberes de forma dinâmica, lúdica e efetiva de forma a permitir a plena inclusão desta parcela significativa de cidadãos brasileiros em nossa sociedade.

Percebemos a relevância deste trabalho quando nos damos conta de que o Brasil tem uma população de 6.5 milhões de cegos; 582 mil deficientes visuais; no mundo a população de cegos chega a 39 milhões e existe pequena produção de material para este público, o que torna difícil a integração plena destes cidadãos na sociedade.

\footnotetext{
${ }^{1}$ O sistema Braille é um processo de escrita e leitura baseado em 64 símbolos em relevo, resultantes da combinação de até seis pontos dispostos em duas colunas de três pontos cada. Pode-se fazer a representação tanto de letras, como algarismos e sinais de pontuação. Ele é utilizado por pessoas cegas e a leitura é feita da esquerda para a direita, ao toque de uma ou duas mãos ao mesmo tempo.
} 
Sentimos grande necessidade em estimular a interação e a inclusão do deficiente visual na sociedade de forma plena. A educação é uma das chaves neste processo e o acesso à informação é para nós fundamental.

No que concerne aos livros, nosso trabalho reside em elaborar projetos gráficos que proporcionem a interatividade entre os públicos estimulando os órgãos sensitivos dos leitores, através de elementos sensoriais. Escrito no sistema Braille e em tinta, permitem o compartilhamento do livro entre os leitores cegos e videntes, fornecendo o alcance do conhecimento cultural para todos os que vivem em sociedade.

No que cabe aos brinquedos, visamos auxiliar em assuntos para os quais material específico se faça necessário na transmissão de diferentes saberes. Estamos desenvolvendo no momento um jogo de batalha naval para apoio ao ensino das coordenadas ortogonais sob demanda da professora de matemática e um kit de apoio às aulas de biologia.

Para desenvolver nosso trabalho estabelecemos parceria com o Instituto Benjamim Constant (doravante IBC) que nos apoia com suas expertises. O IBC é um centro de referência, a nível nacional, para questões da deficiência visual. Seu objetivo é capacitar crianças e adolescentes com deficiência visual, assessorar escolas e instituições, realizar consultas oftalmológicas à população, reabilitar pessoas que perderam a visão, produzir material especializado, impressos em Braille e publicações científicas.

Nossa proposta é unir as nossas expertises em Design com as expertises dos profissionais do instituto no atendimento de crianças cegas e de baixa visão; aproximar nossos alunos de uma população excluída socialmente e pelo mercado editorial criando empatia e capacitação na criação de material especializado.

Para efetivar esta contribuição resolvemos trabalhar no sentido de produzir material grafo-tátil, lúdico para apoio de aprendizagem de crianças cegas, nos aproximar dos professores do instituto, entender as carências e desenvolver material de apelo sensorial ampliando a capacidade dos cegos e os de baixa visão de lidar com os sentidos, aprender de forma lúdica e atender a demandas específicas de ensino-aprendizagem. 
De modo a avançar em nossas pesquisas e, com a colaboração de nossa equipe de trabalho ${ }^{2}$ prosseguimos no sentido de investigar o processo cognitivo das crianças cegas.

O processo cognitivo é o processo de obtenção de conhecimento através da percepção, atenção, associação, memória, raciocínio, juízo, imaginação, pensamento e linguagem. É a forma como o cérebro interpreta, recorda e processa as informações, que são captadas através dos cinco sentidos. Justamente pelos sentidos serem a porta de entrada para essas informações, há a necessidade de estimulá-los corretamente.

A percepção é "um processo dinâmico pelo qual obtemos informações em primeira mão sobre nosso ambiente imediato por meio do uso e integração dos receptores sensoriais ou funcionais" (GIBSON, 1969). Esse processo dinâmico implica em exploração e busca. A percepção se encontra na base dos processos cognitivos e é fundamental para a captação de informações que permitirão a compreensão e relação do indivíduo com o mundo. A experiência obtida através dos sentidos é captada e armazenada para futura utilização.

O processo de formação de conceitos se dá através da inter-relação dos processos cognitivos, logo, ele é extremamente dependente da percepção. Considerando que por volta de $80 \%$ das informações recebidas do meio é adquirida de forma visual, a criança deficiente visual tem uma enorme restrição quanto às características absorvidas do mundo e por consequência, à variedade de conceitos. Barraga (1986) afirma que o indivíduo deficiente visual leva mais tempo para formar conceitos abstratos, mas que isso não significa que a natureza e qualidade da cognição atingida seja significativamente diferente entre cegos e videntes.

Para aumentar a quantidade de informações recebidas, a criança é obrigada a compensar a falta de visão com o uso de outros sistemas sensoriais como a audição e o tato. Por esse motivo, é importante pensar em formas de estimular esses sentidos e motivar as crianças a terem uma participação ativa

\footnotetext{
${ }^{2}$ Desenvolvemos atualmente um projeto de extensão chamado Pleno Sentido, realizado com o apoio da Universidade Federal do Rio de Janeiro (UFRJ) e do Instituto Benjamin Constant (IBC). Destaco a colaboração de lana Oliveira Moreira Alves nos estudos relativos ao processo cognitivo da criança cega.
} 
no processo de percepção, buscando esses estímulos através de iniciativa própria.

Tradicionalmente, são considerados cinco sistemas receptivos: Visual, auditivo, gustativo, olfativo e tátil. Os sentidos têm três funções: Detecção; Transdução e Transmissão. A detecção é a capacidade de perceber tipos específicos de energia. Transdução é a capacidade de transformar essa energia em estímulo nervoso e a transmissão é o que acontece quando o cérebro recebe essa informação e a transmite para o sistema de resposta. (TORO \& BUENO, 2003)

A via visual é considerada o canal sensorial primário na percepção humana. $\mathrm{Na}$ ausência desse, a percepção auditiva passa a ser o canal primário e é responsável por prover a informação que deveria ser recebida pelo canal visual. O canal auditivo e o tato são as principais formas de percepção para a pessoa deficiente visual.

A percepção auditiva tem três principais funções para uma pessoa deficiente visual: em primeiro lugar, ela proporciona a informação que deveria ser recebida pelo sistema visual, serve de meio para orientação e proporciona dados para uma atuação independente no ambiente.

A percepção tátil é um meio de inestimável importância para 0 reconhecimento do ambiente na ausência do sentido visual (TORO \& BUENO 2003). Sua desvantagem sobre a visão é que o tato não vai além do que os braços podem abarcar, enquanto a visão oferece percepção sobre assuntos muito mais distantes. Outra característica que pode ser considerada uma desvantagem é que a percepção de informações com o tato é lenta e analítica, enquanto a visão proporciona uma captação de informações bem mais rápida. Uma ideia errônea que se tem sobre o tato é que o mesmo só pode ser adquirido através das mãos, quando na verdade ele está distribuído por toda a superfície da pele.

As informações recebidas através do tato são difíceis de relacionar com sua origem ou significado, já que explorar aspectos como distância, profundidade, ângulos e formas é uma tarefa muito difícil quando não se dispõe da visão. 
As sensações tátil-cinestésicas permitem que as crianças percebam qualidades como texturas, temperaturas, tamanho, peso, dureza, entre outras. Ao manipular diversos objetos, a criança aprende a receber informações sobre esses objetos e toma consciência da sua capacidade de manipulá-los e alterálos. Estimular essas experiências ajuda a criança a desenvolver técnicas de "aprendizado" tátil para analisar aquela forma e receber uma informação mais completa sobre aquele objeto. O desenvolvimento contínuo dos receptores táteis permite um refinamento na percepção da criança, que passa a identificar características dos objetos com mais clareza.

A representação de objetos de duas dimensões de forma gráfica é um estágio mais avançado do aprendizado tátil-cinestésico já que depende da capacidade de discriminação e de reconhecimento de símbolos. É necessário que a criança reconheça aquele símbolo e interprete o seu significado em cada contexto. É o que acontece muitas vezes com os materiais desenvolvidos em Thermofor $^{3}$. Ao explorar a representação gráfica de um pássaro, por exemplo, a criança precisa entender que aquela forma é apenas uma representação, que não condiz com a realidade do objeto em questão.

A aprendizagem é resultado de uma interação entre os sentidos, o sistema motor e os sentimentos da criança com os objetos que a rodeiam. A criança com deficiência visual possui uma severa restrição em relação à percepção visual. Essa restrição, no entanto, não altera o potencial dessa criança de criar relações com o meio ao seu redor. Ela apenas busca utilizar os recursos ao seu alcance para obter informações e se relacionar com o meio através de outros estímulos sensoriais.

O processo de aprendizagem deve ser um processo ativo. É necessário que a criança se interesse pelo assunto e busque, ela mesma, novas formas de compreender o conceito em questão e relacionar informações. Por meio dessa participação ativa, as crianças adquirem a capacidade de aplicar o conhecimento. Isto é, solucionar problemas, relacionar informações e transferir conhecimentos para novas situações.

\footnotetext{
${ }^{3}$ Termoform é um processo de moldagem por aquecimento que permite criar texturas em acetato. Este material é muito usado por permitir que a pessoa sinta ao toque as formas. Ele, porém, não permite a fabricação de objetos tridimensionais. 
A figura do professor é necessária para instigar este processo ativo. É importante que ocorra a mediação do mesmo para organizar o conteúdo, motivar e orientar o aluno através de perguntas e estímulos que instiguem esse aluno a se envolver ativamente no processo de aprendizado.

Outro aspecto muito importante nesse processo é a motivação. No aprendizado da criança deficiente visual, ela tem um papel ainda mais importante. Quando a criança está motivada, ela demonstra iniciativa para aprender e se mostra mais aberta à recepção de novas informações. A escolha do material didático pode ser um fator muito importante para a motivação dos alunos. Ao disponibilizar materiais didáticos que ofereçam múltiplas formas de estimulação sensorial, o professor cria um ambiente que desperta o interesse do aluno em se relacionar com aquele objeto e a partir dele, receber informações mais completas sobre o assunto em questão, o que futuramente pode ajudar na criação de um novo conceito ou melhor entendimento de um conceito já estabelecido.

Está estabelecido que a percepção sensorial constitui o fundamento do conhecimento e que as crianças deficientes visuais passam pelos mesmos processos de desenvolvimento que as crianças sem nenhum tipo de deficiência. Dito isto, é importante ressaltar a necessidade de estimular essas crianças de forma multissensorial, a fim de que as mesmas tenham a capacidade de relacionar os estímulos entre si e compreender melhor a natureza de cada objeto estudado, reconhecendo esse objeto em qualquer situação, por meio de qualquer estímulo sensorial. Por exemplo, o som do miado de um gato deve vir associado à sensação de maciez de seus pelos ou de aspereza de sua língua. É importante que a criança consiga relacionar um estímulo ao outro e consiga identificar que ambos estão relacionados ao mesmo objeto.

Percebemos assim a importância da criação de material específico para a estimulação da criança cega e partimos para analisar os tipos de publicações voltadas para eles. Deparamo-nos, então, com os seguintes formatos: sistema Braille, áudio books em formato MP3, áudio descrição em formatos Mp3, sap e ao vivo e livro Digital Dayse. Em seguida, analisamos suas vantagens e desvantagens: 


\begin{tabular}{|c|c|c|}
\hline Sistema & Vantagens & Desvantagens \\
\hline Braille & $\begin{array}{l}\text { Único sistema de } \\
\text { alfabetização } \\
\text {.Fundamental para o } \\
\text { processo de ensino } \\
\text { aprendizagem } \\
\text {.Permite } \\
\text { desenvolvimento da } \\
\text { linguagem oral e escrita } \\
\text {.Permite autonomia na } \\
\text { produção textual. }\end{array}$ & $\begin{array}{l}\text { Formato físico de } \\
\text { grandes dimensões } \\
\text {.Leitura cansativa. } \\
\text {.Alto custo }\end{array}$ \\
\hline Audio livro & $\begin{array}{l}\text {.Baixo custo } \\
\text {.Formato MP3 } \\
\text {.Aplicação em diferentes } \\
\text { mídias(CDs, pen drives, } \\
\text { sites) } \\
\text {.Portatil } \\
\text {.Fácil manuseio } \\
\text {.Voz humana sintetizada }\end{array}$ & $\begin{array}{l}\text { Vozes muitas vezes } \\
\text { interpretam o texto } \\
\text {.Não permite a } \\
\text { autonomia na produção } \\
\text { textual }\end{array}$ \\
\hline Audio descrição & $\begin{array}{l}\text { Formato MP3, sap e ao } \\
\text { vivo } \\
\text {.Descrição de cenas } \\
\text { (ilustrações, cinema, } \\
\text { teatro, programas de tv). }\end{array}$ & $\begin{array}{l}\text { Não permite a } \\
\text { autonomia na produção } \\
\text { textual } \\
\text {.Vozes interpretam o } \\
\text { texto }\end{array}$ \\
\hline Livro digital Dayse & $\begin{array}{l}\text {.Gratuito } \\
\text {.Programa de } \\
\text { computador } \\
\text {.Disponibilizado em CD } \\
\text {.Atinge público cego e } \\
\text { de visão sub-normal } \\
\text {.Vários níveis de } \\
\text { ampliação de texto e } \\
\text { permite ouvir a voz } \\
\text { simultaneamente }\end{array}$ & $\begin{array}{l}\text {.Não permite a } \\
\text { autonomia na produção } \\
\text { textual } \\
\text {.Formato PDF } \\
\text { (programa DD reader +) } \\
\text {.Necessita de um } \\
\text { computador } \\
\text {.Sistema confuso } \\
\text {.Comandos na língua } \\
\text { inglesa } \\
\text {.Descrição monótona. }\end{array}$ \\
\hline
\end{tabular}


Optamos em nosso trabalho pelo uso do sistema Braille - acompanhado de impressões em tinta para permitir integração com o público vidente- devido à capacitação para a leitura e produção textual que ele permite.

O Braille é o único sistema que permite ao cego o processo de alfabetização, gera maior autonomia e estimula o desenvolvimento da capacidade verbal e escrita. Deste modo ele é fundamental no processo ensino aprendizagem. Escolhemos, portanto, fazer nossas produções em Braille e em tinta para beneficiar a leitura de cegos, baixa visão e videntes de forma a facilitar a integração entre amigos e familiares com diferentes graus de acuidade visual.

Ao analisarmos alguns livros encontrados no mercado, foram identificadas algumas soluções que representam obstáculos para a leitura de texto e imagens nestas publicações:

1) Capa voltada para videntes muitas vezes sem informação em Braille a pessoa cega depende de outra para fazer a identificação do livro/cd que ela quer ler/ouvir.

2) Uso de pontos no contorno de figuras que leva a pessoa cega a confundir com os pontos do Braille.

3) Uso de relevos ilustrativos, não tridimensionalizados que não permitem a identificação da figura pela pessoa cega.

4) Uso de elementos que são indicadores visuais como representativos que algo que não the corresponde: ex. nuvem representada como algodão.

Decidimos então trabalhar em nossos projetos com o design sensorial conceitual de forma a ampliar o universo lúdico da leitura.

Como queremos atingir o público de baixa visão verificamos que determinadas fontes, sem serifa ${ }^{4}$, com dimensões a partir de 24 pontos e 0 contraste de cores entre figura e fundo são de fundamental importância para a percepção das impressões em tinta.

Buscando entender as necessidades de nosso público alvo e as demandas do IBC, procuramos desenvolver material que ajude a criança no sentido de explorar o universo lúdico dos livros, tornando-os sensorialmente sedutores. 4 Serifa é um traço ou barra que remata cada haste de certas letras, de um ou de ambos os
lados. 
O objetivo é explorar todos os sentidos de forma a despertar a sensorialidade no relacionamento com o artefato e atrair o público vidente especialmente pais e irmãos que não leem Braille - para partilhar a experiência. Pretendemos com isso que o leitor tenha uma leitura diferenciada daquela que já está habituado, agregando valores culturais e sensoriais através do design.

Nossa sociedade tem se tornado cada vez mais uma sociedade de imagens em que o foco no sentido da visão tem sido especialmente desenvolvido. Percebe-se hoje uma atribuição à produção da emoção estética centrada nos aspectos visuais. Esquecesse que o verdadeiro sentido de estética consiste na convocação dos sentidos e que a visão é apenas um deles.

\section{Projeto 1}

O primeiro projeto que desenvolvemos foi a orientação do projeto de TCC "A busca do sensível: abordagem diferenciada para a interação entre cegos e videntes no processo educativo através do design gráfico" de Camille Xavier. Tratava-se de uma adaptação do texto de Clarice Lispector "Os bonecos de Barro" parte do livro "O Lustre". A autora coloca em foco o inconsciente na literatura explorando o universo interior de seus personagens e por isso, foi selecionada para este trabalho. 
O livro foi composto por 23 texturas, 23 páginas de texto em Braille e em tinta, mais a capa. Considerando o tamanho das células de Braille, o tamanho do texto para leitura por pessoas com visão subnormal e o limite de formato suportado pelas impressoras em Braille disponíveis no IBC, o formato do livro foi $29 \times 32 \mathrm{~cm}$. A encadernação deveria permitir o volume das texturas, ter páginas que permitissem manuseio livre, favorecesse a leitura textual e sensorial e indicasse a sequência das páginas.

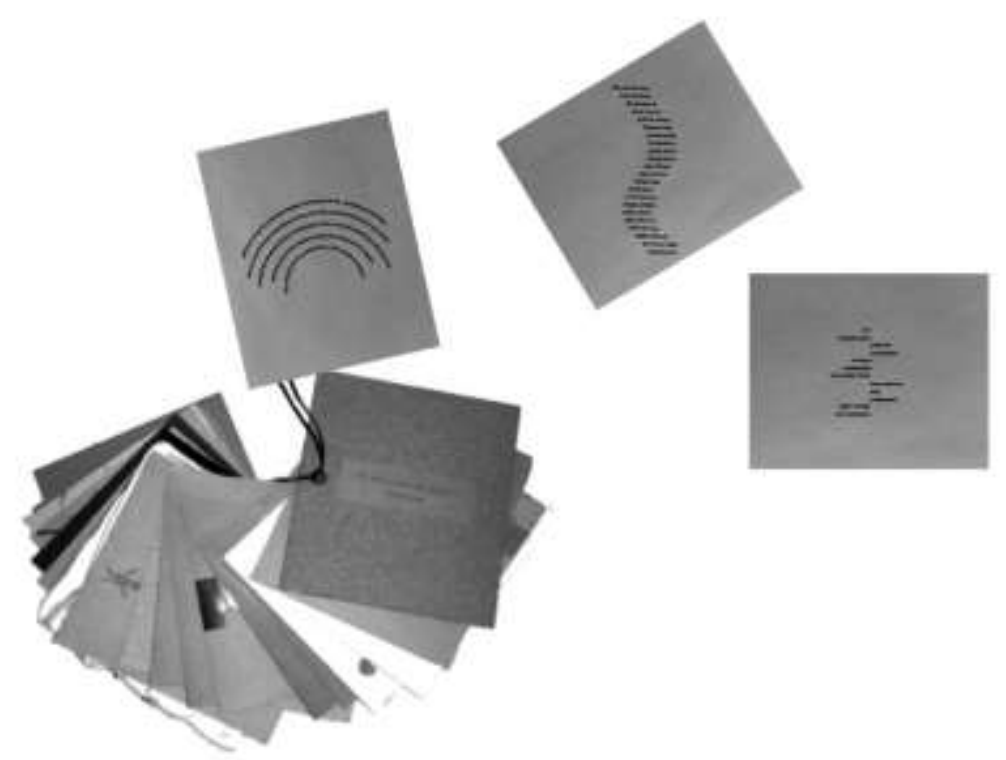

Imagem 1: Protótipo do livro produzido no TCC de Camille Xavier "A busca do sensível: abordagem diferenciada para a interação entre cegos e videntes no processo educativo através do design gráfico"

A transcrição do texto para o Braille foi feita no Braille fácil. A diagramação em tinta buscou formato não convencional capaz de explorar a forma do texto de acordo com as sensações relatadas pelo autor. Visava ainda permitir interatividade e aproximar o leitor da subjetividade do personagem. Foi escolhida uma fonte sem serifa, limpa e de boa legibilidade: Brandon Grotesque ${ }^{5}$, no corpo 24.

As texturas deveriam atender aos seguintes princípios: permitir a interatividade com o livro, oferecer um design com abordagem sensorial, possibilitar a criação de design emocional (memória), fornecer texturas abstratas

${ }^{5}$ Para este projeto temos sempre a preocupação com fontes de fácil leitura. 
e trabalhar com os materiais essenciais destacados pelo texto. Deveria ainda ter ilustrações táteis lúdicas, oferecer informação subjetiva, transmitir as sensações do texto, apresentar formas simples e oferecer o prazer da leitura através do toque.

A identidade visual buscou limpeza, tons terrosos, texturas naturais, orgânicas e rústicas de forma a dar subsídios materiais ao texto. O processo de criação do protótipo foi artesanal e empírico. A capa foi feita em cortiça e o miolo em papel kraft por remeter à terra, ter toque rústico e diferenciado do papel normalmente empregado em publicações em Braille.

\section{Projeto 2}

O segundo trabalho, também uma orientação de trabalho de Conclusão de Curso, era intitulado "Aura e as relíquias mágicas: uma coleção de livros infantis táteis impressos em Braille e em tinta" de Carine Ferreira. Ela redigiu sua própria história criando uma coleção em 4 volumes organizados em dois fichários contendo a descrição de 4 reinos: o do ar, o da água, o da terra e o do fogo. 0 projeto se propõe a utilizar o universo sensorial da criança cega e com visão subnormal de modo a trazer inserção dentro do espaço, tanto real quanto lúdico e imaginativo. Para isso foi criado um livro-brinquedo 6 para ser manipulado livremente pela criança7. A embalagem, a capa, as páginas de texto, os envelopes sensoriais e as relíquias foram pensadas como experiências ricas sensorialmente. A confecção deste trabalho seguiu um caminho artesanal, tendo sido o material impresso em uma máquina Perquins ${ }^{8}$.

Em termos de diagramação, as páginas foram divididas ao meio, sendo o texto em Braille na parte superior e replicado na parte inferior na fonte Avenir ${ }^{9}$, corpo 24 para favorecer a leitura para pessoas de baixa visão.

\footnotetext{
6 Ver Imagem 2.

7 As crianças cegas e de baixa visão são alfabetizadas em diferentes idades dependendo de suas capacidades, idade em que passam a ser assistidas no IBC, entre outros fatores avaliados pela instituição. Em função deste fato produzimos materiais voltados para a fase de aprendizagem na qual as crianças estão inseridas, neste caso Ensino Fundamental I, e não sua faixa etária.

${ }^{8}$ A máquina Perquins é um tipo de máquina de escrever especialmente desenvolvida para escrita em Braille.

${ }^{9}$ A fonte Avenir permite boa leitura e por isso foi a escolhida neste caso
} 
Recursos táteis foram utilizados de forma a reproduzir as provocações lançadas pelo texto bem como a atender seus desafios. No livro 1 , do reino do ar, foram usados elementos para que criança pudesse explorar este elemento: balões estimulam a criança a soprar e a soltar o ar para dentro e para fora do balão, um envelope com vários tipos de pluma mostra a diversidade de nossos pássaros.

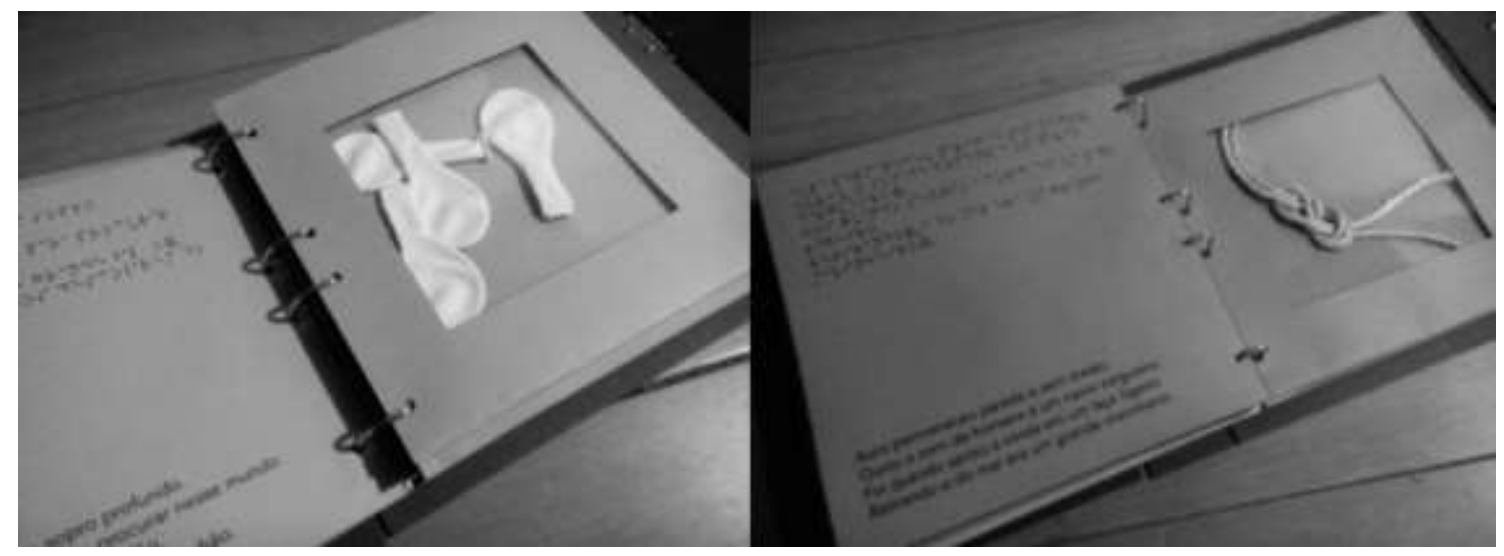

Imagem 2: Protótipo do Livro "Aura e as relíquias mágicas: uma coleção de livros infantis táteis impressos em Braille e em tinta" de Carine Ferreira.

No reino da água, livro 2, de páginas azul claro, um pouco de gel revestido, representa a maleabilidade da água e sua frieza emoliente. O laço de marinheiro aparece em um envelope para representar a corda que permite ao marinheiro salvar a personagem. No reino da terra tem-se a textura da terra seca e flores secas mostrando a riqueza gerada pela terra. No último livro, do reino do fogo, além do papel de cor laranja, gotas de cera derretida foram escorridas sobre uma lamina de forma a dar impressão tátil podendo ainda ser descascado. Bastões de carvão são usados para demonstrar a capacidade de combustão do fogo.

Para facilitar o manuseio,os livros foram organizados aos pares, em fichários. As relíquias conquistadas pela criança após a leitura de cada livro foram desenvolvidas em tecnologia de impressão 3D. Tanto os livros quanto as relíquias foram acondicionadas em sacola de tecido.

\section{Projeto 3}


O projeto de TCC "Desenvolvimento de kit de complementação pedagógica para crianças deficientes visuais utilizando a tecnologia de impressão 3D" de lana Alves tem como objetivo utilizar novas tecnologias para resolver problemas de acessibilidade e melhorar a qualidade de vida da criança deficiente visual, garantindo mais acesso à informação. O projeto alia novas tecnologias e meios de produção digitais ao design e à experiência do usuário para criar modelos que auxiliem no ensino de biologia, oferecendo aos professores novos recursos que visam melhorar a absorção de conteúdo por parte das crianças.

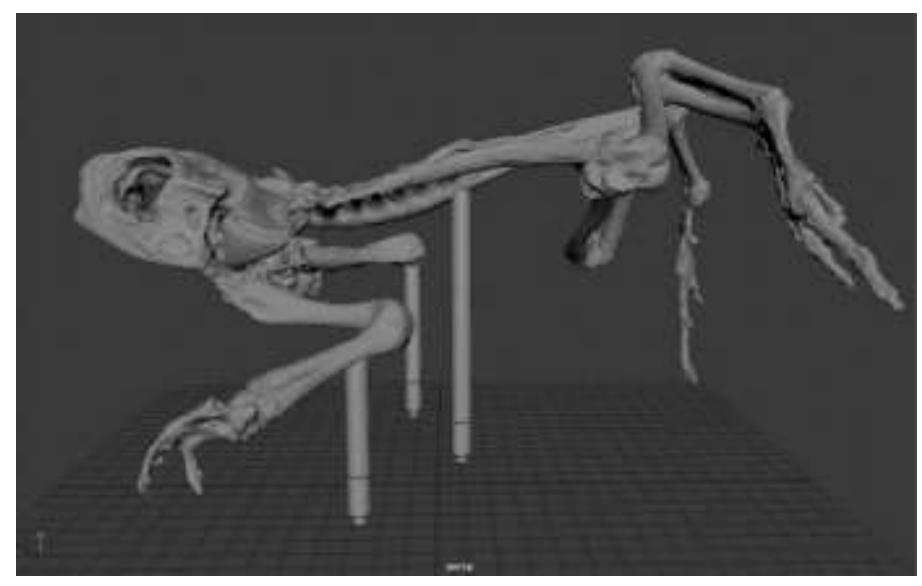

Imagem 3: Desenho realizado em software 3D para a prototipagem do modelo

Este projeto, ainda em andamento, realizou estudos em torno do desenvolvimento cognitivo e da recepção e interpretação da informação pela criança cega e da importância da exploração dos sentidos para a aquisição de conceitos. Seguindo essa linha, estão sendo desenvolvidos objetos que estimulam a aprendizagem tátil-cinestésica, isto é, a aprendizagem que acontece através do uso do tato.

Recursos didáticos são recursos físicos que têm o objetivo de auxiliar a educação, facilitando e tornando a aprendizagem mais eficiente. Destaca-se a importância dos recursos didáticos na educação de pessoas deficientes visuais pois tal como a criança de visão normal, a deficiente visual necessita de motivação para a aprendizagem; alguns recursos podem suprir lacunas na aquisição de informações pela criança deficiente visual; e o manuseio de diferentes materiais possibilita o treinamento da percepção tátil, facilitando a 
discriminação de detalhes e suscitando a realização de movimentos delicados com os dedos, conforme apontam Cerqueira e Ferreira (1996).

É necessário destacar que existe uma escassez de recursos didáticos no mercado, e ainda assim, a maioria dos disponíveis é fabricado em Thermoform, material que permite que o aluno perceba as formas, porém não os volumes.

A biologia é uma disciplina que a princípio pode parecer abstrata, tanto para alunos com deficiência visual quanto para alunos videntes. No entanto, para os alunos de visão normal, há o recurso visual que esclarece conceitos através de desenhos, gráficos, tabelas e etc. . Um aluno com deficiência visual não pode se beneficiar desse tipo de material e por esse motivo, é importante pensar no desenvolvimento de recursos táteis que possam facilitar o entendimento da disciplina e favorecer a aprendizagem para este aluno.

Após a fase inicial de concepção, foram feitos esboços, que passaram por uma fase de revisão pelos professores do IBC antes da fase de impressão e distribuição para as crianças. Foi realizada a modelagem no software $3 D^{10}$ e em seguida serão impressos protótipos de baixa fidelidade. Por fim, o último passo no projeto será aplicar esses modelos em sala de aula e analisar a sua efetividade. Será importante levar em consideração os feedbacks das crianças para melhorar os modelos em uma nova versão.

\section{Projeto 4}

O projeto, "Pleno Sentido: em busca do empoderamento da criança com deficiência visual" das bolsistas de extensão Fátima de Abreu e Anna Beatriz Accioly, consiste na criação de um livro-objeto com uma história feita por e para crianças com deficiência visual acompanhado de objetos que remontam à temática "praia".

O objetivo é criar um cenário de aventura que encoraje e empodere a criança com deficiência a explorar lugares e a viver novas experiências.

\footnotetext{
10 Softwares 3D são programas de computador que permitem a construção de modelos em três dimensões de forma a viabilizar sua posterior impressão em impressoras especiais para este tipo de trabalho.
} 
Queremos não só trazê-los para o foco do produto, mas também mostrar sua capacidade de criação de conteúdo.

O livro traz a história de uma criança cega e suas experiências sensoriais vividas em um dia na praia, suas aventuras e descobertas. A ideia é trabalhar com elementos do cotidiano das crianças e integralizar a aprendizagem tanto pelos procedimentos encampados pela metodologia de ensino de Paulo Freire ${ }^{11}$ quanto pela articulação com atividade proporcionada pelo Instituto que consiste em passeios à praia próxima ao IBC. De modo lúdico, pretendemos que este livro seja um facilitador na educação básica e popular da criança portadora de deficiência visual.

O livro poderá ser usado por pessoas videntes e com baixa visão, por isso além do Braille, o texto será também impresso em tinta e com tipografia ampliada. Em relação às soluções do projeto, serão usadas peças texturizadas e sons que estimulam a conexão entre leitura e o lúdico/imagético infantil e poucas ilustrações de formas mais simples, mantendo o alto contraste para a visualização pelas crianças com baixa visão.

Para os indivíduos de baixa visão é recomendado o uso de um suporte a 45 graus de inclinação para apoio do livro. Desta forma pensamos para o livro uma embalagem específica que permitirá este apoio e acondicionará o livro e objetos, facilitando o transporte.

$\mathrm{Na}$ presente etapa do projeto as alunas, a autora e a professora da turma estão realizando oficinas de contação de histórias com os alunos do IBC, para a produção de conteúdo.

${ }^{11}$ Em especial os livros Educação como prática da liberdade, Rio de Janeiro: Paz e Terra, 1989 e Pedagogia do oprimido, New York: Herder \& Herder, 1970. 
Imagem 4 e 5: $\mathrm{Na}$

suporte para o livro parte inferior o tabuleiro do

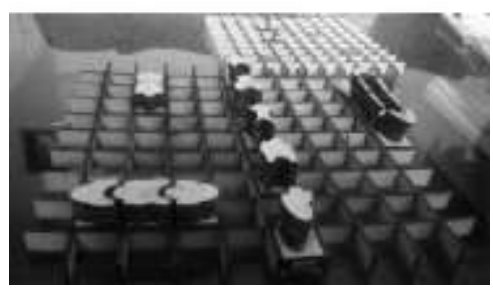

parte superior se vê o referente ao projeto 4 e na jogo referente ao projeto 5 .

\section{Projeto 5}

O projeto das alunas extensionistas Laise dos Anjos e Luiza Eiras, em fase de desenvolvimento, contempla a "Adaptação do jogo Batalha Naval para nãovidentes e baixa visão" com o objetivo de auxiliar o estudo das coordenadas cartesianas.

A motivação para a adaptação do jogo surgiu a partir da entrada em sala de aula das alunas, que buscavam verificar as demandas e lacunas existentes relativas aos materiais didáticos e lúdicos. A professora do $\mathrm{IBC}$, da turma de reforço de matemática de alunos com baixa visão ou não videntes, destacou a importância do jogo batalha naval como auxílio no ensino da disciplina, especialmente para o entendimento da noção de coordenadas, dos eixos x e y, e como seria útil o uso de uma versão adaptada em sala de aula.

O objetivo é que o jogo possa ser utilizado tanto como material de apoio para as aulas no instituto quanto como um jogo que favoreça a integração de pessoas com dificuldades ou perdas visuais e pessoas com a visão plena uma vez que pode ser jogado pelos dois públicos.

O importante nesta adaptação é que seja possível jogar tão bem quanto no original e que os materiais utilizados, as texturas disponíveis, espaçamentos dos tabuleiros e formato das peças sejam agradáveis ao toque para os não-videntes.

Haverá ainda indicação das letras e números em Braille e em tinta, alto relevo das divisões nas linhas do tabuleiro e encaixe das peças nos espaços nas 
divisões da grelha; os barcos terão texturas para que possam ser diferenciados e também cores em alto contraste. Um espaço do tabuleiro se destina a um ábaco simples de dezenas e de unidades, para auxiliar a contagem de pontos e ainda na parte de baixo um espaço para guardar as peças do jogo. A grelha será feita com MDF e os barcos em resina. Na próxima etapa faremos o protótipo do projeto para testagem com as crianças.

\section{Considerações finais}

O estudo aqui apresentado revela nossa investigação no campo da criação de material grafo tátil para crianças cegas e de baixa visão. No fechamento de cada projeto ele é passado para uma revisora cega do IBC e testado com o público alvo. A experiência que envolve professores do IBC, da UFRJ, e alunos de ambas as instituições tem sido muito producente contribuindo para a inclusão social do cego e da pessoa com baixa visão.

\section{REFERÊNCIAS}

BARRAGA, N. C. Necesidades de aprendizaje de los niños discapacitados visuales (trad. S.E. Crespo "Learning needs of visually handicapped children" (original no publicado).) En Discapacidad visual,. ICEVH. Córdoba, Argentina, №46 Núm. 16, 161-210 1986

CERQUEIRA, J. B.; FERREIRA, E. M. B. Recursos didáticos na educação especial. Rev. Benjamin Constant, Rio de Janeiro, n. 5, p. 1-6, 1996.

FREIRE, P. Educação como prática da liberdade. Rio de Janeiro: Paz e Terra, 1989 . Pedagogia do oprimido, New York: Herder \& Herder, 1970.

GIBSON, E. J. Principles of Perceptual Learning and Development. Appleton-Century-Crofts, Nova lorque, 1969.

MARTIN, M. B.; BUENO, S. T.; Deficiência visual: aspectos psicoevolutivos e educativos. $1^{\underline{a}}$ ed. São Paulo: Santos, 2003. 